\title{
Defective complex I assembly due to C20orf7 mutations as a new cause of Leigh syndrome
}

\author{
M Gerards, ${ }^{1,2}$ W Sluiter, ${ }^{3}$ B J C van den Bosch, ${ }^{1,2}$ L E A de Wit, ${ }^{3}$ C M H Calis, ${ }^{1}$ \\ M Frentzen, ${ }^{4} \mathrm{H}$ Akbari, ${ }^{4} \mathrm{~K}$ Schoonderwoerd, ${ }^{5} \mathrm{H}$ R Scholte, ${ }^{3,6} \mathrm{R} \mathrm{J}$ Jongbloed, ${ }^{1}$ \\ A T M Hendrickx, ${ }^{1}$ I F M de Coo, ${ }^{7}$ H J M Smeets ${ }^{1,2}$
}

\begin{abstract}
- Supplementary tables 1 and 2 are published online only. To view these files please visit the journal online (http://jmg.bmj. com)

${ }^{1}$ Department of Genetics and Cell Biology, Unit Clinical Genomics, Maastricht University, Maastricht, The Netherlands

${ }^{2}$ School for Oncology and Developmental Biology, Maastricht University, Maastricht, The Netherlands ${ }^{3}$ Department of Biochemistry, Mitochondrial Research Unit, Erasmus MC, Rotterdam, The Netherlands

${ }^{4}$ Unit of Botany, Institute for Biology I, RWTH Aachen University, Aachen, Germany ${ }^{5}$ Department of Clinical Genetics, Erasmus MC, Rotterdam, The Netherlands ${ }^{6}$ Department of Neuroscience, Erasmus MC, Rotterdam, The Netherlands

${ }^{7}$ Department of Neurology, Erasmus MC, Rotterdam, The Netherlands
\end{abstract}

\section{Correspondence to} Dr H J M Smeets, Department of Genetics and Cell Biology, PO Box 616, 6200 MD Maastricht, the Netherlands;

Bert.Smeets@molcelb. unimaas.nl

Received 5 March 2009

Revised 19 May 2009

Accepted 25 May 2009

Published Online First

18 June 2009

\section{(2) UNLOCKI:}

This paper is freely available online under the BMJ Journals unlocked scheme, see http:// jmg.bmj.com/site/about/ unlocked.xhtml

\section{ABSTRACT}

Background Leigh syndrome is an early onset, progressive, neurodegenerative disorder with developmental and motor skills regression. Characteristic magnetic resonance imaging abnormalities consist of focal bilateral lesions in the basal ganglia and/or the brainstem. The main cause is a deficiency in oxidative phosphorylation due to mutations in an mtDNA or nuclear oxidative phosphorylation gene.

Methods and results $A$ consanguineous Moroccan family with Leigh syndrome comprise 11 children, three of which are affected. Marker analysis revealed a homozygous region of $11.5 \mathrm{Mb}$ on chromosome 20 , containing 111 genes. Eight possible mitochondrial candidate genes were sequenced. Patients were homozygous for an unclassified variant (p.P193L) in the cardiolipin synthase gene (CRLS1). As this variant was present in $20 \%$ of a Moroccan control population and enzyme activity was only reduced to $50 \%$, this could not explain the rare clinical phenotype in our family. Patients were also homozygous for an amino acid substitution (p.L159F) in C20orf7, a new complex I assembly factor. Parents were heterozygous and unaffected sibs heterozygous or homozygous wild type. The mutation affects the predicted S-adenosylmethionine (SAM) dependent methyltransferase domain of C20orf7, possibly involved in methylation of NDUFB3 during the assembly process. Blue native gel electrophoresis showed an altered complex I assembly with only $30-40 \%$ of mature complex I present in patients and $70-90 \%$ in carriers. Conclusions A new cause of Leigh syndrome can be a defect in early complex I assembly due to C20orf7 mutations.

\section{INTRODUCTION}

Leigh syndrome (MIM 256000) is an early onset, progressive, neurodegenerative disorder with a characteristic neuropathology consisting of focal, bilateral lesions in one or more areas of the central nervous system, including basal ganglia, thalamus, cerebellum, brainstem and spinal cord. The lesions are areas of demyelination, gliosis, necrosis, spongiosis, or capillary proliferation. Clinical symptoms depend on which areas of the central nervous system are affected. The most common underlying cause is a defect in oxidative phosphorylation (OXPHOS). ${ }^{1}$ Leigh syndrome can be associated with a deficiency of any of the mitochondrial respiratory chain complexes. ${ }^{2}$ The disorder is genetically heterogeneous and can be caused by mutations in the mtDNA and a variety of nuclear genes of the OXPHOS and pyruvate dehydrogenase system.
In structural complex I genes, mutations have been found in the mtDNA ND1, ${ }^{3} \mathrm{ND} 2,{ }^{4} \mathrm{ND} 3,{ }^{5}$ $N D 5,{ }^{6}$ and $N D 6^{7}$ genes and in the nuclear NDUFV1, ${ }^{8}$ NDUFS1, 9 NDUFS $3,{ }^{10}$ NDUFS $4,{ }^{11}$ NDUFS $7,{ }^{12}$ NDUFS $8,{ }^{13}$ NDUFA $11^{14}$ and NDUFA $2^{15}$ genes. In addition, mutations have been reported in the genes for the flavoprotein subunit A of complex II $\left(S D H A^{16}\right)$ and for the complex III assembly factor BCS1L. ${ }^{17}$ Mutations in complex IV genes include mtDNA encoded $M T C O 3^{18}$ and nuclear encoded COX 10, ${ }^{19}$ COX 15, ${ }^{20}$ SCO2, ${ }^{21}$ and SURF1, ${ }^{22}$ which are involved in complex IV assembly. Several mutations were detected in the mtDNA encoded ATPase 6 (complex V). ${ }^{23}$ Additional mtDNA mutations have been described for the tRNA genes for valine, ${ }^{24}$ lysine, ${ }^{25}$ tryptophan $^{26}$ and leucine. ${ }^{27}$

Leigh syndrome may also be caused by mutations in components of the pyruvate dehydrogenase complex (PDHA1 pyruvate dehydrogenase, $\alpha 1$-subunit and $D L D$, dihydrolipoamide dehydrogenase $)^{2829}$ and in the gene encoding the leucine-rich PPR motif containing protein (LRPPRC) ${ }^{30}$ Due to this extreme genetic heterogeneity, in many cases it is difficult to establish a genetic diagnosis in Leigh syndrome, especially if no additional clinical or biochemical data are available to pinpoint specific candidate genes. In order to identify the genetic cause in a consanguineous Moroccan family we performed homozygosity mapping and positional candidate gene analysis. A pathogenic amino acid substitution was identified in a new complex I assembly factor C20orf7 ${ }^{31}$ which caused Leigh syndrome with a diminished complex I activity, making defective complex I assembly an important pathogenic cause of Leigh syndrome.

\section{SUBJECTS AND METHODS Subjects}

In a consanguineous family from Morocco with 11 children, three boys presented with Leigh syndrome (figure 1), two of whom were clinically investigated. The third affected sib succumbed for unknown reason at the age of 36 years in Morocco. The disease course is comparable in the two living patients (age 29 and 23 years). At the age of 3 they presented with a progressive spasticity with involvement of arms and legs. At the age of 5 they developed a diminished facial expression. Computed tomography (CT) scanning of the brain of patient IV7 at the age of 5 years showed hypodensity and slight atrophy of the caudate nuclei and the putamen (figure 2a). There is a widening of the frontal horns of the cerebral ventricles. One year 

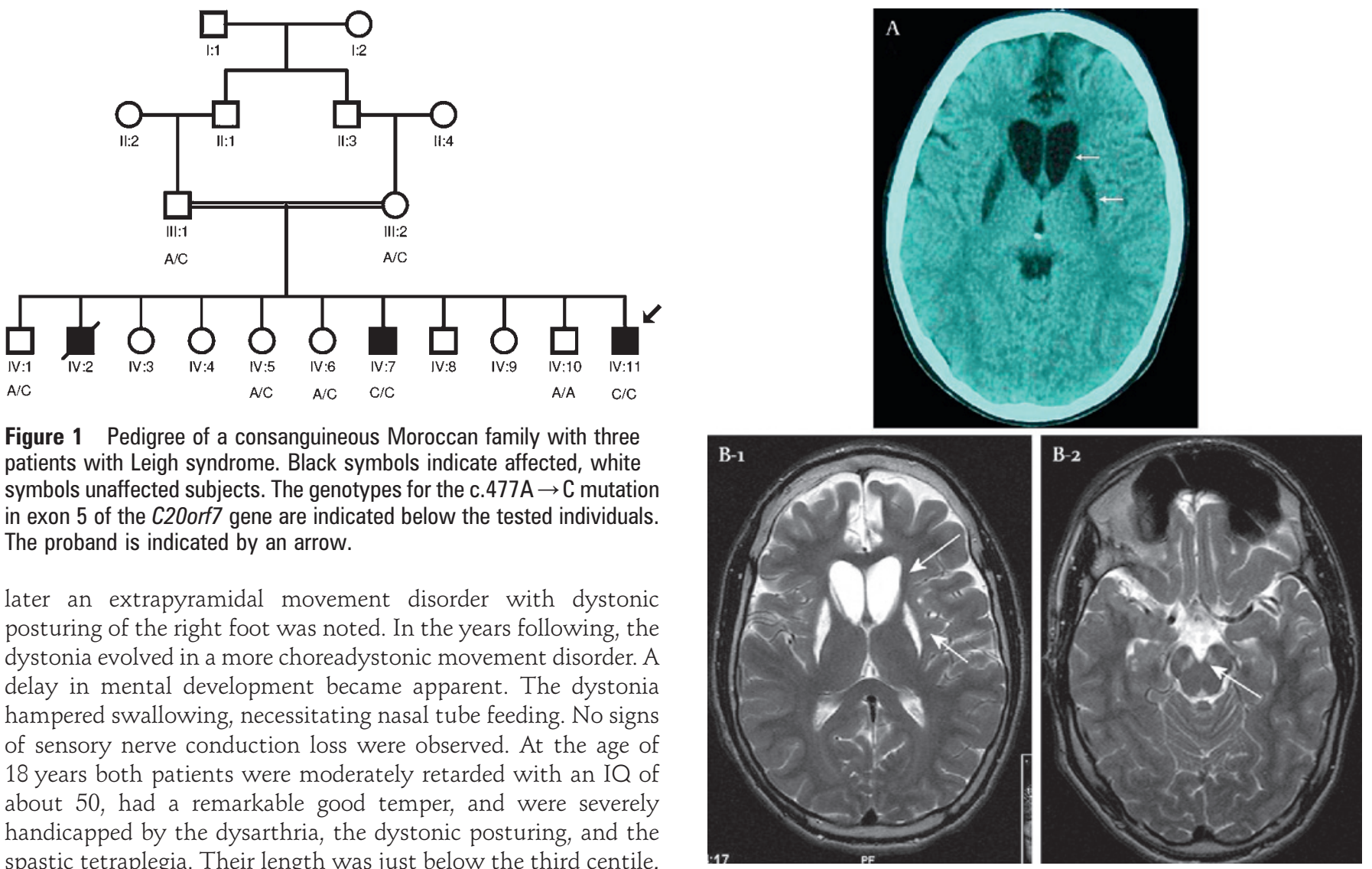

Figure 1 Pedigree of a consanguineous Moroccan family with three patients with Leigh syndrome. Black symbols indicate affected, white symbols unaffected subjects. The genotypes for the c.477A $\rightarrow \mathrm{C}$ mutation in exon 5 of the C20orf7 gene are indicated below the tested individuals. The proband is indicated by an arrow.

later an extrapyramidal movement disorder with dystonic posturing of the right foot was noted. In the years following, the dystonia evolved in a more choreadystonic movement disorder. A delay in mental development became apparent. The dystonia hampered swallowing, necessitating nasal tube feeding. No signs of sensory nerve conduction loss were observed. At the age of 18 years both patients were moderately retarded with an IQ of about 50, had a remarkable good temper, and were severely handicapped by the dysarthria, the dystonic posturing, and the spastic tetraplegia. Their length was just below the third centile, but this was not different from the unaffected sibs and parents.

In both patients the electroencephalogram (EEG) was normal. Pattern visual evoked responses demonstrated normal responses with N135 at $141 \mathrm{~ms}$. Cranial magnetic resonance imaging (MRI) of patient IV11 at the age of 23 years showed a small residual nucleus caudatus and lesions in the basal ganglia consisting of prolongation of both T1 and T2 weighted signals in the caudate nucleus, putamen, the substantia nigra and a discrete abnormality in the peri-aquaductal grey area, and also discrete bifrontal global atrophy (figure $2 b$ ). After reaching puberty, the progression of the disease seemed to stop or slowed down. Orthopaedic interventions were necessary, because of complications of the movement disorders such as development of an equinovarus contracture in both feet and the development of a c-shaped scoliosis. Oral daily drug treatment consisted of carnitine $330 \mathrm{mg}$, riboflavin $30 \mathrm{mg}$, biotin $10 \mathrm{mg}$, and thiamine $100 \mathrm{mg}$. Parents and the other children are in good health and further family history is unremarkable. Informed consent was provided by the family for scientific investigations and publication.

\section{Metabolic and enzymatic measurements}

Routine metabolic workup was performed on the blood, urine and cerebrospinal fluid of the patients to rule out other inborn errors of metabolism including blood glucose, lactate, amino acids, acid/ base status, ammonia, creatine kinase, carnitine, acylcarnitines, very long chain fatty acids, uric acid, B12, folate, cholesterol, isoelectric focusing of transferrin (for CDG, congenital disorders of glycosylation), biotinidase, lysosomal enzymes, purine and pyrimidine values; urine amino acids, organic acids, oligosaccharides, and mucopolysaccharide screening; cerebrospinal fluid (CSF) glucose, lactate, amino acids, and neurotransmitter measurements. A needle muscle biopsy from vastus lateralis muscle was performed at 22 and 29 years of age in patients IV11 and IV7, respectively. Complex I activity was determined in

Figure 2 Computed tomography (CT) and magnetic resonance imaging (MRI) of patients IV7 and IV11. respectively. (A) CT scan of patients IV7 brain at the age of 5 years. The CT scan shows a hypodensity and slight atrophy of the caudate nuclei and the putamen (arrows) and a widening of the frontal horns of the cerebral ventricles. (B-1) Cranial MRI of patient IV11 at the age of 23 years. Prolongation of T2 weighted signals in the residual part of the nucleus caudatus and putamen and (B-2) at the level of the midbrain of the substantia nigra (arrow).

duplicate in these biopsy specimens and in peripheral blood lymphocytes (PBMCs) of patients IV7 and IV11 and their unaffected brother IV10. Assays to determine complex I and citrate synthase activities and protein content of the mitochondrial fractions were performed as described before. ${ }^{32-35}$

Fibroblasts were grown in Dulbecco's modified Eagle's medium (DMEM; Gibco by Invitrogen, Carlsbad, CA, USA) supplemented with 10\% fetal bovine serum (FBS, Gibco), $50 \mu \mathrm{g} /$ $\mathrm{ml}$ of uridine (Acros Organics Geel, Belgium) and 50 units $/ \mathrm{ml}$ penicillin and $50 \mu \mathrm{g} / \mathrm{ml}$ streptomycin (BioWhittaker, Walkersville, $\mathrm{MD}$, USA). To isolate mitochondria, cells were resuspended in isolation buffer containing $0.25 \mathrm{M}$ sucrose, $10 \mathrm{mM}$ Tris- $\mathrm{HCl}$ $\mathrm{pH} 7.5$, and $1 \mathrm{mM}$ EDTA and homogenised on ice (10 strokes at $1500 \mathrm{rpm})$. Homogenates were centrifuged at $1600 \mathrm{~g}$ at $4^{\circ} \mathrm{C}$ for $10 \mathrm{~min}$ to remove cell debris and nuclei. Subsequently, mitochondria were pelleted from the supernatant at $10000 \mathrm{~g}$ at $4^{\circ} \mathrm{C}$ for $10 \mathrm{~min}$. Cardiolipin synthase (CLS) activity was determined in mitochondrial membranes after swelling the isolated organelles twice in $10 \mathrm{mM}$ Bis-Tris propane- $\mathrm{HCl}$ buffer $\mathrm{pH} 7.4$ and sedimenting mitochondrial membranes, which were finally resuspended in this Bis-Tris propane- $\mathrm{HCl}$ buffer containing $50 \%$ glycerol to a protein concentration of about $1 \mathrm{mg}$ protein $/ \mathrm{ml}$. Mitochondrial protein, $1-6 \mu \mathrm{g}$, was used for CLS assays in a total volume of $50 \mu \mathrm{l}$, as described before ${ }^{36}$ except that the reaction mixtures were incubated at $37^{\circ} \mathrm{C}$ for $1 \mathrm{~h}$. 


\section{Homozygosity mapping}

Homozygosity mapping was performed, using the Affymetrix GeneChip Human Mapping 10K 2.0 Array (Santa Clara, CA, USA) for a whole genome analysis. Samples were processed and labelled according to the instructions of the manufacturer, hybridised in a GeneChip hybridisation oven followed by wash and stain with the GeneChip Fluidics Station 450, and scanning with the GeneChip Scanner 3000 (Affymetrix). Genotypes were generated by the GeneChip DNA analysis software (GDAS). The Copy Number Analysis Tool (CNAT, Affymetrix) was used to detect homozygosity regions in patient samples. Candidate regions were defined as homozygosity regions present in the patient samples but not in other family samples. Parametric lod scores were calculated using the Merlin package (version 1.1.2) ${ }^{37}$ with a recessive disease model.

\section{Mutation analysis}

The mtDNA was screened for deletions by long range polymerase chain reaction (PCR) and heteroplasmic point mutations by denaturing high performance liquid chromatography (DHPLC) analysis as described before. ${ }^{38}$ The exons and flanking introns of the human CRLS1 and C20orf7 genes were amplified with specific intronic primers (supplementary data table 1).

PCR was performed with 50 ng DNA using Taq-polymerase and buffer (Invitrogen, Carlsbad, CA, USA) with a final concentration of $1.5 \mathrm{mM} \mathrm{MgCl}_{2}$. Cycle conditions were: $94^{\circ} \mathrm{C}$ for $5 \mathrm{~min}$, followed by 33 cycles of $94^{\circ} \mathrm{C}$ for $1 \mathrm{~min}, 54^{\circ} \mathrm{C}$ for $1 \mathrm{~min}$, and $72^{\circ} \mathrm{C}$ for $1.5 \mathrm{~min}$ with a final elongation step of $72^{\circ} \mathrm{C}$ for $7 \mathrm{~min}$. PCR products were directly sequenced with the PRISM Ready Reaction Sequencing Kit (Applied Biosystems, Foster City, CA, USA) on an ABI3100 automatic sequencer (Applied Biosystems).

\section{Mutation specific restriction digestion}

A mutation specific restriction digestion assay was developed for the c.477A $\rightarrow$ C substitution in the C20orf7 gene. A total of $10 \mu \mathrm{l}$ PCR product of exon 5 was digested for $1 \mathrm{~h}$ at $37^{\circ} \mathrm{C}$ with NheI and MseI, followed by a heat inactivation for $20 \mathrm{~min}$ at $65^{\circ} \mathrm{C}$. Msel does not cleave if the mutation is present. Nhe1 was added to eliminate a constant band of $127 \mathrm{bp}$, which would otherwise trouble the interpretation. After digestion, the samples were resolved on a 3\% agarose gel presenting a fragment of $109 \mathrm{bp}$ for wild type samples compared to a $130 \mathrm{bp}$ fragment for the mutant.

\section{Blue native-polyacrylamide gel electrophoresis (BN-PAGE)}

Mitochondria were isolated from $\mathrm{PBMCs}^{33} 34$ and incubated for $10 \mathrm{~min}$ on ice in lysis buffer $(50 \mathrm{mM} \mathrm{NaCl}, 5 \mathrm{mM}$ aminocaproic acid, $50 \mathrm{mM}$ imidazole, $\mathrm{pH} 7.0$ ) containing 1\% Triton X-100 and supplemented with complete protease inhibitors (Roche Diagnostics $\mathrm{GmbH}$, Mannheim, Germany), $1 \mathrm{mM}$ 4-(2-aminoethyl)benzenesulphonyl-fluoride hydrochloride (Roche) and $2 \mathrm{mM}$ diisopropyl fluorophosphate (Fluka Chemica, Sigma-Aldrich, St. Louis, MO, USA). Next, $2.5 \mu \mathrm{g}$ of PBMC mitochondrial protein was processed for one dimensional BN-PAGE as previously described $^{39}$ using NativePAGE $3-12 \%$ gels (Invitrogen, Breda, The Netherlands) and Western transferred on PVDF membrane. Immunoreactive proteins were detected by mouse monoclonal antibodies against complex I subunits ND1 (Santa Cruz Biotechnology, Santa Cruz, CA, USA), NDUFA9 and complex II subunit $70 \mathrm{kDa} F p$ (MitoSciences, Eugene, OR, USA). Proteins were visualised using biotinylated secondary antibodies against mouse IgG (Amersham Biosciences, Little Chalfont,
Bucks, UK), streptavidin-biotinylated horseradish peroxidase complex (Amersham) and SuperSignal West Femto (Pierce Biotechnology, Rockford, IL, USA). The molecular weights of the protein bands were estimated by a NativeMark Unstained Protein Standard (Invitrogen). Images were acquired using a calibrated densitometer (GS-800; Bio-Rad, Bio-Rad Laboratories, Hercules, CA, USA) and quantified using PDQuest Advanced software package (version 8.0.1 build 055; Bio-Rad).

\section{RESULTS \\ Metabolic and enzymological studies of two sibs with Leigh syndrome}

Routine metabolic workup in urine and blood plasma of patients IV7 and IV11 only revealed a slight increase in blood alanine values without a raise in blood or urine lactic acid. Glucose tolerance test was normal. Also the methionine, vitamin B12, folic acid, purines and pyrimidines, and S-adenosylmethionine (SAM) concentrations were in the normal range $(86-128 \mathrm{nmol} / \mathrm{l}$ ) Cerebrospinal fluid examination at the age of 5 years of patient IV7 showed an increased lactic acid of $5 \mathrm{mmol} / 1$ (controls $<2.0$ mmol/l). Complex I activity, normalised by citrate synthase activity, was in muscle and PBMCs of patient IV7 respectively $36 \%$ and $6 \%$ of the controls and in patient IV11 respectively $48 \%$ and $33 \%$. Activities of other OXPHOS complexes were only available for patient IV11 and were 105\%, 123\% and $87 \%$ of the control values for complex II, III and IV, respectively. Morphological studies show an increase in average fibre diameter. Staining for succinate tetrazolium reductase and NADH tetrazolium reductase showed increased subsarcolemmal activities. Staining for cytochrome $c$ oxidase demonstrated some COX negative fibres.

\section{Homozygosity mapping in the Leigh syndrome family}

Molecular genetic analysis was initially directed at the mtDNA. First, the entire mtDNA of the muscle sample of patient IV7 was tested for deletions by long range PCR, but no mtDNA deletion was observed (data not shown). Next, the mtDNA was screened by DHPLC analysis, ${ }^{38}$ but no heteroplasmic point mutations were detected, making the involvement of a nuclear gene likely. Both parents, two affected (IV7 an IV11) and four unaffected sibs (IV1, IV5, IV6 and IV10) were tested with the Human Mapping 10K GeneChips. CNAT analysis revealed a large homozygosity region of $11.5 \mathrm{Mb}$ on chromosome 20 (from $2.4 \mathrm{Mb}$ to $13.9 \mathrm{Mb}$, supplementary data table 2), yielding a parametric LOD score of 2.3. This region contained a total of 111 genes. The selection of genes with a putative mitochondrial function was based on the MitoP2 database (http://www.mitop.de:8080/mitop2/) and the list of Calvo et $a{ }^{40}$ which is based on a variety of criteria, including mitochondrial import sequence and co-expression with known mitochondrial genes. A total of eight candidate genes- $I D H 3 B$ (isocitrate dehydrogenase $3 \quad\left[\mathrm{NAD}^{+}\right] \quad \beta$-subunit), MRPS26 (mitochondrial ribosomal protein S26), PANK2 (pantothenate kinase 2), CRLS1 (cardiolipin synthase 1), CDS2 (CDP-diacylglycerol synthase (phosphatidate cytidylyltransferase) 2), HAO1 (hydroxyacid oxidase (glycolate oxidase) 1), PAK7 (p21 (CDKN1A)-activated kinase 7), and C20orf7-were selected for mutation analysis.

\section{Mutation detection in eight candidate genes}

Exons and flanking intron sequences of the eight candidate genes were analysed by conventional sequence analysis. Only two potentially pathogenic variants were found in the CRLS1 and C20orf7 gene, while in the other six genes no pathogenic 
mutations were identified. Patient IV11 was homozygous for a c.592C $\rightarrow \mathrm{T}$ mutation in exon 4 of the CRLS1 gene, changing proline at position 193 into leucine. Patient IV7 was homozygous mutant as well, both parents and two sibs were heterozygous, and one sib was wild type. The mutation was neither reported before nor present in any of the single nucleotide polymorphism (SNP) databases (NCBI SNP, Genome Variation Server and MutationDiscovery.com). Analysis of a Moroccan and Dutch control population (resp. 92 and 294 alleles) using sequence analysis revealed an allele frequency of, respectively, 20\% and $10 \%$, which was unexpected given the absence of the variant in the SNP databases. CLS activity was reduced to $50-56 \%$ in fibroblasts of patients compared to unrelated wild-type control fibroblasts. Based on the high frequency of the (heterozygous) mutation in the controls and the residual activity of CLS of about $50 \%$, we concluded that this mutation could not by itself explain the rare clinical features in this family.

A second homozygous mutation was identified in the C20orf7 gene. Both patients (IV7 and IV11) were homozygous for an A-to-C transversion at nucleotide 477 in exon 5 of isoform 1 (NM_024120.3), whereas both parents and two other sibs were heterozygous and one sib was wild type (figures 1 and $3 a$ ). Two isoforms of C20orf7 are currently known, consisting of, respectively, 345 amino acids (isoform 1 (NM_024120.3), containing exons 1-11), and 317 amino acids (isoform 2 (NM_001039375.1), containing exons $1-4$ and $6-11)$. The mutation is present in isoform 1 only. The mutation changed a leucine at position 159 to phenylalanine in the highly conserved (from man to Drosophila) S-adenosylmethionine (SAM) dependent methyltransferase domain of the protein (figure $3 b$ ). Analysis with the program SOPM $^{41}$ shows that the secondary structure is likely to change due to breakage of an $\alpha$ helix in the mutant protein (data not shown). SOPM uses sequence information and similarities to predict secondary protein structures. The mutation was not present in 110 Moroccan and 312 Dutch alleles, supporting a pathogenic role for the mutation.

\section{p.L159F substitution in C20orf7 disturbs complex I assembly}

Recently, Sugiana et al ${ }^{31}$ reported that C20orf7 resides within the mitochondrial matrix with a function in the assembly or stability of an early complex I assembly intermediate that contains among others ND1. Therefore we tested if the p.L159F substitution affected complex I assembly. BN-PAGE (Blue-Native polyacrylamide gel electrophoresis) was performed in PBMCs of patients IV7 and IV11 (homozygous mutant), heterozygous carriers III1, III2 and IV6 and the homozygous wild type sib IV10 with antibodies against ND1 and NDUFA9 to detect the mature $880 \mathrm{kDa}$ complex I. BN-PAGE showed a decrease of mature complex I in patient samples IV7 and IV11 to $30-40 \%$ of the control values. In carriers (III1, III2 and IV6) this was $70-90 \%$ of the normal amount of complex I (figure 4A, B).

\section{DISCUSSION}

Leigh syndrome is a progressive neurodegenerative disorder, which can be caused by mutations in the mtDNA and a variety of known and still unknown nuclear genes. Due to this genetic heterogeneity it is often difficult to establish a genetic diagnosis and characterise the pathological process involved. This study reports an early complex I assembly defect due to a missense mutation in the new complex I assembly factor C20orf7 as the pathological cause. The c20orf7 mutation affects the highly conserved S-adenosylmethionine (SAM) dependent methyltransferase domain, which may be involved in methylation of
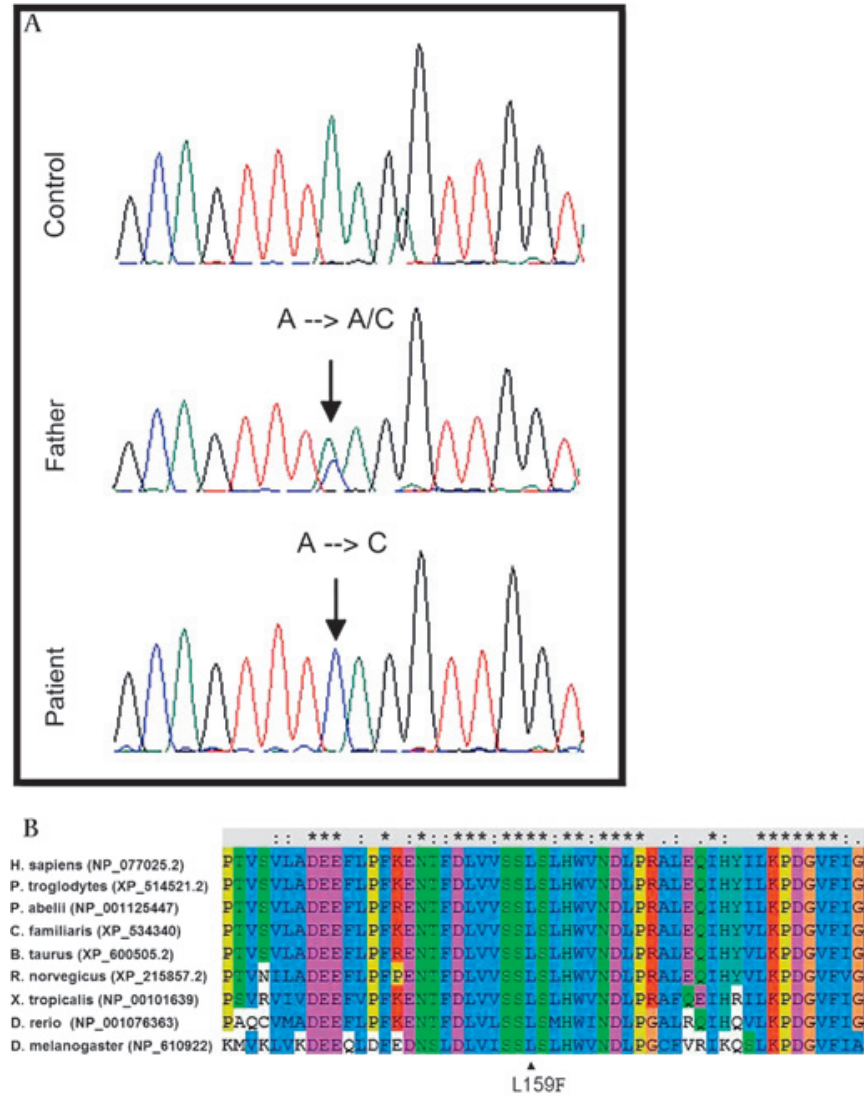

Figure 3 Mutation analysis in the C20orf7 gene reveals a c.477A $\rightarrow C$ mutation changing leucine at position 159 to phenylalanine. (A) Sequence analysis of exon 5 of the C20orf7 gene. (B) Conservation of leucine 159 from man to Drosophila (ClustalW).

NDUFB3 as a critical step in early complex I assembly as postulated by Sugiana et al. ${ }^{31}$ The patients do not display the full picture of Leigh syndrome and clinically the phenotype has overlap with infantile bilateral striatal necrosis (IBSN, MIM 271930), but the involvement of structures in the brain stem make it more compatible to Leigh syndrome. Defects in complex I assembly/stability leading to enzymatic deficiency have been reported before in Leigh syndrome due to mutations in structural or accessory subunits. ${ }^{42}$ To our knowledge this is, next to c8orf38, ${ }^{31}$ the second defect in a genuine complex I assembly factor in Leigh syndrome, which adds defective complex I assembly as an important pathological concept to the growing list of pathogenic causes of Leigh syndrome.

When these studies were in progress, a family with a lethal neonatal form of complex I deficiency with a mutation in the C20orf7 gene was reported. ${ }^{31}$ Patients were homozygous for a missense mutation in exon 7 of the C20orf7 gene (NM_024120.3), leading to a substitution of leucine 229 to proline, which is present in both isoforms. Patients' fibroblasts almost completely lacked the mature complex I holo-enzyme. ND1 or an intermediate complex containing ND1 was not present, suggesting an early assembly defect. In concordance with their observation, a decrease of mature complex I relative to complex II down to $30-40 \%$ compared to normal is observed in our patients' PMBCs as determined by BN-PAGE.

The clinical manifestation of the p.L159F mutation in this family is less severe than the neonatal lethal p.L229P mutation, and also the complex I deficiency and assembly defect are less pronounced. Either the mutation or the affected domain of 
A

NDUFA9

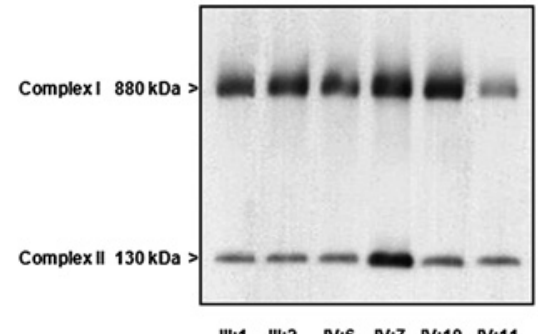

III:1 III:2 N:6 N:7 N:10 N:11
ND1

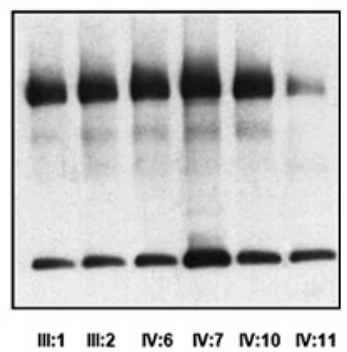

B

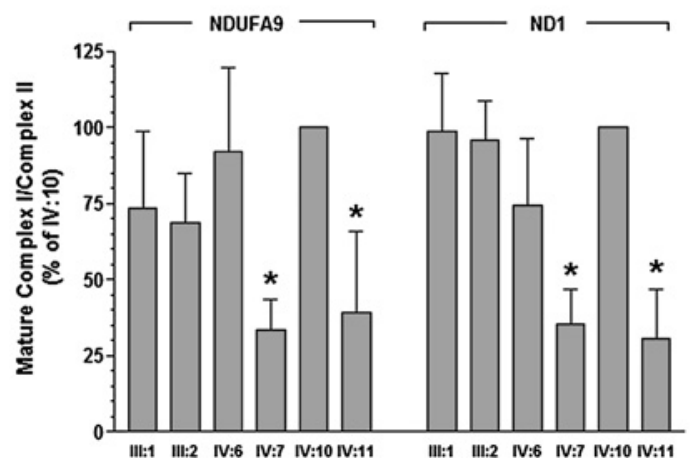

Figure 4 Complex I assembly is altered in patient PBMC. Mitochondria were isolated from PBMC of wild-type $(A / A)$, carriers $(A / C)$ and a patient (C/C) donors, solubilised in $1 \%$ Triton X-100, and subjected to BN-PAGE and Western immunoblot analysis and quantified. Complex I detected by an antibody to the $39 \mathrm{kDa}$ subunit (NDUFA9) or ND1 subunit is at approximately $880 \mathrm{kDa}$, and complex II detected by an antibody to the $70 \mathrm{kDa}$ subunit is at approximately $130 \mathrm{kDa}$. (A) After $10-30 \mathrm{~s}$ exposure time. (B) Histogram of A showing the density volumes of complex I normalised by complex II as percentage of the wild-type (IV:10) donor, with error bars representing the SEM of three or four gels. ${ }^{*} \mathrm{p}<0.05$ lower than the wild-type donor (IV:10) as compared by Student $t$ test.

C20orf7 is less essential for proper assembly or the defect may be partially rescued in our patients by its absence in isoform 2 . As no difference was observed in the relative expression of the two isoforms in different tissues, including brain, liver, heart, skeletal muscle, kidney, adipose tissue, thyroid, blood and endothelium (data not shown), it is unlikely that tissue specific expression of the two isoforms can explain the variation in clinical expression. It remains unclear whether the second isoform leads to a protein with the same function as isoform 1 . Further studies are required to resolve the exact pathological or rescue process occurring.

\section{Web resources}

The URLs for data presented herein are as follows:

- Online Mendelian Inheritance in Man (OMIM), http://www. ncbi.nlm.nih.gov/0mim/

- MitoP2 database, http://www.mitop.de:8080/mitop2/

- NCBI SNP database, http://www.ncbi.nlm.nih.gov/sites/ entrez?db=snp

- Genome Variation Server, http://gvs.gs.washington.edu/GVS/

- Nucleotide Variation and Mutation Database MutationDiscovery.com, http://www.mutationdiscovery.com/md/MD.com/ home_page.jsp

- ClustalW, http://www.ebi.ac.uk/Tools/clustalw2/index.html

- SOPM, http://npsa-pbil.ibcp.fr/cgi-bin/npsa_automat.pl?page= npsa_sopm.html

Patients were not only homozygous for the mutation in C20orf7, but also for a common variant in the CRLS1 gene. As 1\% of the Dutch and $4 \%$ of the Moroccan population is predicted to be homozygous for this mutation, this would imply a disease frequency of 1-4 in 100, if the CRLS1 variant would be the genetic cause. This is not the case. However, the reduction of CLS activity, which is unlikely to cause clinical symptoms by itself, may contribute to the disease phenotype in case the OXPHOS is already affected by another defect, like in this family. So, C20orf7 mutations are a new cause of Leigh syndrome due to an early complex I assembly defect. Disease manifestations are mutation specific and may be modified by additional mutations in other genes, like CRLS1.

Acknowledgements This work was supported by a EU grant to the MitoCircle project (Sixth Framework Program, contr. no. 005260). We thank Prof Dr B Oostra for supplying a Morroccon control panel.

Competing interests None.

Patient consent Obtained.

Provenance and peer review Not commissioned; externally peer reviewed.

\section{REFERENCES}

1. Dahl HH. Getting to the nucleus of mitochondrial disorders: identification of respiratory chain-enzyme genes causing Leigh syndrome. Am J Hum Genet 1998;63:1594-7.

2. Rotig A, Munnich A. Genetic features of mitochondrial respiratory chain disorders. J Am Soc Nephrol 2003;14:2995-3007.

3. Moslemi AR, Darin N, Tulinius M, Wiklund LM, Holme E, Oldfors A. Progressive encephalopathy and complex I deficiency associated with mutations in MTND1. Neuropediatrics 2008;39:24-8.

4. Hinttala R, Smeets R, Moilanen JS, Ugalde C, Uusimaa J, Smeitink JA, Majamaa K Analysis of mitochondrial DNA sequences in patients with isolated or combined oxidative phosphorylation system deficiency. J Med Genet 2006; $43: 881-6$.

5. McFarland R, Kirby DM, Fowler KJ, Ohtake A, Ryan MT, Amor DJ, Fletcher JM, Dixon JW, Collins FA, Turnbull DM, Taylor RW, Thorburn DR. De novo mutations in the mitochondrial ND3 gene as a cause of infantile mitochondrial encephalopathy and complex I deficiency. Ann Neurol 2004;55:58-64.

6. Taylor RW, Morris AA, Hutchinson M, Turnbull DM. Leigh disease associated with a novel mitochondrial DNA ND5 mutation. Eur J Hum Genet 2002; 10:141-4.

7. Ugalde C, Triepels RH, Coenen MJ, van den Heuvel LP, Smeets R, Uusimaa J, Briones P, Campistol J, Majamaa K, Smeitink JA, Nijtmans LG. Impaired complex I assembly in a Leigh syndrome patient with a novel missense mutation in the ND6 gene. Ann Neurol 2003;54:665-9.

8. Schuelke M, Smeitink J, Mariman E, Loeffen J, Plecko B, Trijbels F, Stöckler-Ipsiroglu S, van den Heuvel L. Mutant NDUFV1 subunit of mitochondrial complex I causes leukodystrophy and myoclonic epilepsy. Nat Genet 1999;21:260-1.

9. Benit P, Chretien D, Kadhom N, de Lonlay-Debeney P, Cormier-Daire V, Cabral A, Peudenier S, Rustin P, Munnich A, Rötig A. Large-scale deletion and point mutations of the nuclear NDUFV1 and NDUFS1 genes in mitochondrial complex I deficiency. Am J Hum Genet 2001;68:1344-52.

10. Benit P, Slama A, Cartault F, Giurgea I, Chretien D, Lebon S, Marsac C, Munnich A, Rötig A, Rustin P. Mutant NDUFS3 subunit of mitochondrial complex I causes Leigh syndrome. J Med Genet 2004;41:14-17.

11. Budde SM, van den Heuvel LP, Janssen AJ, Smeets RJ, Buskens CA, DeMeirleir L, Van Coster R, Baethmann M, Voit T, Trijbels JM, Smeitink JA. Combined enzymatic complex I and III deficiency associated with mutations in the nuclear encoded NDUFS4 gene. Biochem Biophys Res Commun 2000;275:63-8.

12. Lebon S, Rodriguez D, Bridoux D, Zerrad A, Rötig A, Munnich A, Legrand A, Slama A A novel mutation in the human complex I NDUFS7 subunit associated with Leigh syndrome. Mol Genet Metab 2007;90:379-82.

13. Loeffen J, Smeitink J, Triepels R, Smeets R, Schuelke M, Sengers R, Trijbels F, Hamel B, Mullaart R, van den Heuvel L. The first nuclear-encoded complex I mutation in a patient with Leigh syndrome. Am J Hum Genet 1998;63:1598-608.

14. Berger I, Hershkovitz E, Shaag A, Edvardson S, Saada A, Elpeleg O. Mitochondrial complex I deficiency caused by a deleterious NDUFA11 mutation. Ann Neurol 2008:63:405-8.

15. Hoefs SJ, Dieteren CE, Distelmaier F, Janssen RJ, Epplen A, Swarts HG, Forkink M, Rodenburg RJ, Nijtmans LG, Willems PH, Smeitink JA, van den Heuvel LP. NDUFA2 complex I mutation leads to Leigh disease. Am J Hum Genet 2008;82:1306-15.

16. Bourgeron $T$, Rustin $P$, Chretien D, Birch-Machin M, Bourgeois $M$, Viegas-Péquignot $E$, Munnich A, Rötig A. Mutation of a nuclear succinate dehydrogenase gene results in mitochondrial respiratory chain deficiency. Nat Genet 1995;11:144-9. 
17. de Lonlay P, Valnot I, Barrientos A, Gorbatyuk M, Tzagoloff A, Taanman JW Benayoun E, Chrétien D, Kadhom N, Lombès A, de Baulny HO, Niaudet P, Munnich A, Rustin $P$, Rötig A. A mutant mitochondrial respiratory chain assembly protein causes complex III deficiency in patients with tubulopathy, encephalopathy and liver failure. Nat Genet 2001;29:57-60.

18. Keightley JA, Hoffbuhr KC, Burton MD, Salas VM, Johnston WS, Penn AM, Buist NR, Kennaway NG. A microdeletion in cytochrome c oxidase (COX) subunit III associated with COX deficiency and recurrent myoglobinuria. Nat Genet 1996;12:410-16.

19. Valnot I, von Kleist-Retzow JC, Barrientos A, Gorbatyuk M, Taanman JW, Mehaye B, Rustin P, Tzagoloff A, Munnich A, Rötig A. A mutation in the human heme A: farnesyltransferase gene (COX10) causes cytochrome c oxidase deficiency. Hum Mol Genet 2000:9:1245-9.

20. Oquendo CE, Antonicka H, Shoubridge EA, Reardon W, Brown GK. Functional and genetic studies demonstrate that mutation in the COX15 gene can cause Leigh syndrome. J Med Genet 2004:41:540-4.

21. Papadopoulou LC, Sue CM, Davidson MM, Tanji K, Nishino I, Sadlock JE, Krishna S, Walker W, Selby J, Glerum DM, Coster RV, Lyon G, Scalais E, Lebel R, Kaplan P, Shanske S, De Vivo DC, Bonilla E, Hirano M, DiMauro S, Schon EA. Fatal infantile cardioencephalomyopathy with COX deficiency and mutations in SCO2, a COX assembly gene. Nat Genet 1999:23:333-7.

22. Tiranti V, Hoertnagel K, Carrozzo R, Galimberti C, Munaro M, Granatiero M, Zelante L, Gasparini P. Marzella R, Rocchi M, Bayona-Bafaluy MP, Enriquez JA, Uziel G, Bertini E, Dionisi-Vici C, Franco B, Meitinger T, Zeviani M. Mutations of SURF-1 in Leigh disease associated with cytochrome c oxidase deficiency. Am J Hum Genet 1998:63:1609-21.

23. de Coo IF, Smeets HJ, Gabreels FJ, Arts N, van Oost BA. Isolated case of menta retardation and ataxia due to a de novo mitochondrial T8993G mutation. Am J Hum Genet 1996:58:636-8.

24. McFarland R, Clark KM, Morris AA, Taylor RW, Macphail S, Lightowlers RN, Turnbull DM. Multiple neonatal deaths due to a homoplasmic mitochondrial DNA mutation. Nat Genet 2002;30:145-6.

25. Shoffner JM, Lott MT, Lezza AM, Seibel P, Ballinger SW, Wallace DC. Myoclonic epilepsy and ragged-red fiber disease (MERRF) is associated with a mitochondrial DNA tRNA(Lys) mutation. Cell 1990:61:931-7.

26. Santorelli FM, Tanji K, Sano M, Shanske S, El-Shahawi M, Kranz-Eble P, DiMauro S, De Vivo DC. Maternally inherited encephalopathy associated with a single-base insertion in the mitochondrial tRNATrp gene. Ann Neurol 1997;42:256-60.

27. Kobayashi Y, Momoi MY, Tominaga K, Momoi T, Nihei K, Yanagisawa M, Kagawa Y, Ohta S. A point mutation in the mitochondrial tRNA(Leu)(UUR) gene in MELAS (mitochondrial myopathy, encephalopathy, lactic acidosis and stroke-like episodes). Biochem Biophys Res Commun 1990;173:816-22.

28. Grafakou 0, Oexle K, van den Heuvel L, Smeets R, Trijbels F, Goebel HH, Bosshard N, Superti-Furga A, Steinmann B, Smeitink J. Leigh syndrome due to compound heterozygosity of dihydrolipoamide dehydrogenase gene mutations. Description of the first E3 splice site mutation. Eur J Pediatr 2003:162:714-18.
29. Matthews PM, Marchington DR, Squier M, Land J, Brown RM, Brown GK. Molecular genetic characterization of an X-linked form of Leigh's syndrome. Ann Neurol 1993;33:652-5.

30. Mootha VK, Lepage P, Miller K, Bunkenborg J, Reich M, Hjerrild M, Delmonte T, Villeneuve A, Sladek R, Xu F, Mitchell GA, Morin C, Mann M, Hudson TJ, Robinson B Rioux JD, Lander ES. Identification of a gene causing human cytochrome $\mathrm{c}$ oxidase deficiency by integrative genomics. Proc Natl Acad Sci U S A 2003; 100:605-10.

31. Sugiana C, Pagliarini DJ, McKenzie M, Kirby DM, Salemi R, Abu-Amero KK, Dahl HH, Hutchison WM, Vascotto KA, Smith SM, Newbold RF, Christodoulou J, Calvo S, Mootha VK, Ryan MT, Thorburn DR. Mutation of C20orf7 disrupts complex I assembly and causes lethal neonatal mitochondrial disease. Am J Hum Genet 2008;83:468-78

32. de Wit LE, Scholte HR, Sluiter W. Correct assay of complex I activity in human skin fibroblasts by timely addition of rotenone. Clin Chem 2008;54:1921-2; author reply 1922-4

33. de Wit LE, Spruijt L, Schoonderwoerd GC, de Coo IF, Smeets HJ, Scholte HR, Sluiter W. A simplified and reliable assay for complex I in human blood lymphocytes. J Immunol Methods 2007;326:76-82.

34. de Wit LE, Sluiter W. Chapter 9 Reliable assay for measuring complex I activity in human blood lymphocytes and skin fibroblasts. Methods Enzymol 2009;456:169-81.

35. Vydt TC, de Coo RF, Soliman Ol, Ten Cate FJ, van Geuns RJ, Vletter WB, Schoonderwoerd K, van den Bosch BJ, Smeets HJ, Geleijnse ML. Cardiac involvemen in adults with m.3243A > G MELAS gene mutation. Am J Cardiol 2007; 99:264-9.

36. Nowicki M, Muller F, Frentzen M. Cardiolipin synthase of Arabidopsis thaliana. FEBS Lett 2005; 579:2161-5.

37. Abecasis GR, Cherny SS, Cookson WO, Cardon LR. Merlin-rapid analysis of dense genetic maps using sparse gene flow trees. Nat Genet 2002;30:97-101.

38. van Den Bosch BJ, de Coo RF, Scholte HR, Nijland JG, van Den Bogaard R, de Visser M, de Die-Smulders CE, Smeets HJ. Mutation analysis of the entire mitochondrial genome using denaturing high performance liquid chromatography. Nucleic Acids Res 2000;28:E89.

39. van Raam BJ, Sluiter W, de Wit E, Roos D, Verhoeven AJ, Kuijpers TW. Mitochondrial membrane potential in human neutrophils is maintained by complex III activity in the absence of supercomplex organisation. PLOS ONE 2008;3:e2013.

40. Calvo S, Jain M, Xie X, Sheth SA, Chang B, Goldberger OA, Spinazzola A, Zeviani M, Carr SA, Mootha VK. Systematic identification of human mitochondrial disease genes through integrative genomics. Nat Genet 2006;38:576-82.

41. Combet C, Blanchet C, Geourjon C, et al. NPS@: network protein sequence analysis. Trends Biochem Sci 2000;25:147-50.

42. Lazarou M, Thorburn DR, Ryan MT, McKenzie M. Assembly of mitochondrial complex I and defects in disease. Biochim Biophys Acta 2009:1793:78-88. 